\title{
Heranças recriadas: \\ especificidades da construção do Império do Brasil
}

Recriated Heritages: Specificities of

the Brazilian Empire's Formation

Cecília Helena de Salles Oliveira

Museu Paulista USP

\section{Resumo}

0 texto problematiza alguns dos argumentos apresentados por IImar R. de Mattos no artigo Construtores e Herdeiros. Procura realçar a originalidade da contribuição do historiador para a compreensão do delineamento do Império na primeira metade do século XIX, privilegiando a noção de "expansão para dentro" bem como as imbricações, no âmbito do discurso político e da memória, entre o passado colonial como herança e o futuro como projeto nacional.

\begin{abstract}
This paper discusses some of the statements presented by IImar R. de Mattos in his article "Builders and Heirs". The author aims to emphasize the originality of Mattos's contributions for a better understanding of the Empire's specificities during the first half of the $19^{\text {th }}$ century, mainly his argument of an "inland expansion". It focuses also, through the analyses of political discourses and memoirs, on the relations between the Empire's colonial past, interpreted as a heritage, and its future as a national project.
\end{abstract}

\section{Palavras-chave}

Império do Brasil, política/ administração, historiografia, Independência. Keywords

Brazilian Empire, politics/administration, historiography, Independence. 
"...Eia, a glória que os dárdanos espera, do italo tronco os descendentes nossos que a fama ilustrarão dos seus maiores, Hei de explicar-te e aprenderás teu fado... ...tu, Romano cuida o mundo em reger, terás por artes A paz e a lei a ditar, e os povos todos Poupar submissos debelar soberbos..." Virgílio, Eneida, livro VI

"... Os homens fazem sua própria história, mas não a fazem como querem; não a fazem sob as circunstâncias de sua escolha e sim sob aquelas com que se defrontam diretamente, legadas e transmitidas pelo passado. A tradição de todas as gerações mortas oprime como um pesadelo o cérebro dos vivos. $E$ justamente quando parecem empenhados em revolucionar-se a si e às coisas, em criar algo que jamais existiu, precisamente nesses períodos em crise revolucionária, os homens conjuram ansiosamente em seu auxílio os espíritos do passado, tomando-Ihes emprestado os nomes, os gritos de guerra e as roupagens, a fim de apresentar-se nessa linguagem...." Marx, 18 Brumário.

1

IImar Rohloff de Mattos. "Construtores e herdeiros. A trama de interesses na construção da unidade política."
Difícil tarefa a do debatedor diante de artigo, com o qual, em linhas gerais, concorda, que se mostra tão erudito e ao mesmo tempo provocativo ${ }^{1}$. As reflexões formuladas por IImar Mattos ensejam um leque amplo de questões sobre a Independência e o delineamento do Império e da nação, na primeira metade do século XIX. Além de evidenciarem pressupostos historiográficos que alteram, a meu ver, os modos mais conhecidos de abordar o tema e o período.

Desse modo, meus comentários não pretendem abranger o conjunto do texto. Atenho-me a alguns pontos que, em minha interpretação, melhor assinalam a originalidade da contribuição do historiador, particularmente no âmbito dos significados que atribui ao Império e à "expansão para dentro", marco da peculiar formação da nacionalidade brasileira no século XIX.

\section{0 passado entre heranças e representações}

Já o título do artigo merece especial atenção: "Construtores e herdeiros: a trama de interesses na construção da unidade política". A formulação não é casual, nem quanto à ordem em que as expressões foram colocadas, tampouco no que diz respeito à partícula de ligação utilizada. Construtores e herdeiros, ao menos na primeira metade do século XIX e em termos do debate apresentado, não são opções políticas opostas ou excludentes. A despeito dos argumentos centrais explicitarem em maior profundidade as heranças e suas implicações, protagonistas que tiveram atuação incongruente, como Evaristo da Veiga e José Bonifácio, foram ao mesmo tempo construtores e herdeiros, sendo precisamente um dos horizontes do autor as mediações entre o passado da monarquia portuguesa e o futuro do Império do Brasil.

Como os homens que experimentaram as paixões e entusiasmos da Independência, e que presenciaram o Fico ou os festejos da Aclamação, poderiam escapar a seu próprio tempo e agir sem carregar práticas e noções, que por anos tinham sido seus referentes culturais? Mas, como elaborar e colocar em prática uma nova organização política - separada doravante da monarquia portuguesa - sem romper com costumes e tradições que não espelhavam os desejos de novidade e transformação imbricados à Independência? De que modo compreender o percurso histórico no qual uma parte do todo - a 
2

Ver, especialmente, pp.7-11 do artigo.

3

Karl Marx. 018 Brumário e Cartas a Kugelmann. Trad. Leandro Konder. Rio de Janeiro: Paz e Terra, 1969, pp. 17-18.

4

Virgílio. Geórgicas/ Eneida. Trad. A F. de Castilho e M. 0 Mendes. São Paulo: Jackson, 1948, pp. 111-388. 0 trecho escolhido para epígrafe encontra-se nas pp. 242-243. Sobre a obra consultar também o site www.paideuma. hpg.ig.com, organizado por Zélia de Almeida Camargo, da FFLCH/USP.

5

Paulo Pereira de Castro. "Política e administração de 1840 a 1848". In: Sérgio Buarque de Holanda (org). História Geral da Civilização Brasileira. Tomo II, $2^{\circ}$ vol., 2a. ed. São Paulo: Difel, 1967, pp. 522-ss.

6

Izabel Andrade Marson. O império do progresso. São Paulo: Brasiliense, 1987, pp. 412SS.

7

François Hartog. Memória de Ulisses. Trad. J. Brandão. Belo Horizonte: Editora da UFMG, 2004, pp. 28-32.

8

Idem, pp. 29-30
América portuguesa, o "Império do Brasil"2 - se constituiu em entidade política autônoma e soberana, preservando-se o antigo nome embora com outro sentido?

Indagações como essas, suscitadas pela prazerosa leitura do artigo, levaram-me a retomar obras de Virgílio e Marx. Esse último autor, porque expôs um dos movimentos pelos quais as sociedades modernas se conformam e se projetam para si mesmas: a complexa dinâmica na qual passado e futuro imaginados se afirmam e se negam nas práticas e nos discursos dos que experimentaram a configuração das nações e dos Estados nacionais na primeira metade do século XIX33. E Virgílio porque foi referencial apropriado por alguns dos principais protagonistas da obra política que então se delineava no Brasil 4.

Pelo menos em duas ocasiões nas décadas de 1840 e 1850, a narrativa de Anquises, na cena retratada no Livro VI, a "Descida aos infernos", foi recuperada. Nela, a personagem preveniu o filho, Enéias, sobre seu destino, alertando-o de que suas ações, no futuro, resultariam na fundação de Roma e do Império. Dessa parte da obra foi extraída a expressão "poupar submissos debelar soberbos" usada, em 1844, para definir a política do gabinete Almeida Torres que propunha uma "conciliação", de caráter compulsório como frisou Paulo Pereira de Castro, entre os moderados das diferentes facções partidárias, justificando-se que o exclusivismo político era uma das razões pelas quais os "interesses nacionais" não conseguiam se sobrepor a questiúnculas locais e de grupos, o que inviabilizava a unidade política da naçã $0^{5}$.

Reeditada, em 1853, a mesma frase sustentou o pressuposto conhecido como "ponte de ouro" defendido por Nabuco de Araújo e Honório Hermeto Carneiro Leão, o Marquês de Paraná, entre outros políticos. A "ponte de ouro" foi interpretada, naquele momento e por seus idealizadores, como um dos apanágios dos estadistas, pois o que se pretendia era agasalhar os que se subordinavam aos desígnios do Estado imperial, castigando-se e cooptando-se os "radicais" para que não impedissem a obra de unificação e centralização nacional. Como observou Izabel Marson, também essa "conciliação" implicou práticas autoritárias e compulsórias. 0 argumento segundo o qual o "progresso" material e moral derivava de interesses comuns a liberais e conservadores, voltados ambos para reformas tidas como necessárias à integridade do Estado, apontava, conforme indicou a historiadora, para o exercício da dominação política de certas facções proprietárias sobre outras, e sobre o conjunto da sociedade, e para a imposição de um projeto de Império, em detrimento da memória de outros projetos e possibilidades históricas ${ }^{6}$.

Mas, os trechos selecionados de Virgílio e de Marx não evidenciam somente modos específicos e históricos de instrumentalização política do passado pelo presente. Conduzem, ao mesmo tempo, a aprofundamentos que podem ajudar a explicitar a complexidade implicada nos "construtores e herdeiros" de que trata IImar Mattos.

Seguindo observações de François Hartog sobre as significações das narrativas de viagens na Antigüidade clássica7, é possivel considerar a Eneida como continuação da Odisséia, mas de maneira invertida. Como propõe o autor, a obra de Virgílio, formulada no momento da ascensão de Augusto, seria uma viagem sem retorno. Enquanto Ulisses deseja retornar para Ítaca, deixando Tróia destruída, Enéias abandona Tróia em chamas para não mais voltar. Ou melhor, para fundar uma nova Tróia, realizar quase que uma colonização forçada a fim de que a cidade não pereça. 0 mar será o lugar de longo exílio até que seja encontrada a orla onde se possa abrigar e semear um novo começo. Segundo Hartog, "fundar a cidade ou a raça romana será sim fazer ressurgir o reino de Tróia; a fundação é refundação, é repetição embora, ao mesmo tempo, completamente inédita." ${ }^{8}$. Antes, no entanto, Enéias terá que guerrear, estabelecer fronteiras sempre movediças, registrar memórias e, também, recortar alteridades. Originários dos troianos, quem são, contudo, os 
9

A esse respeito, consultar especialmente a obra de Izabel Marson op. cit.

10

Claude Lefort. As formas da História. Trad. M. Chauí e L R. S. Forte. São Paulo: Brasiliense, 1979, pp. 238-ss.

11

IImar R. de Mattos,. op. cit, p. 1. romanos? Como se diferenciam dos gregos e dos bárbaros? Hartog discute, então, de que modo a narrativa de viagem é expressão do movimento de formulação de alteridades, o que é fundamental do ponto de vista do debate em foco. Para descobrir-se romano, mais do que reconhecer uma origem no passado, era preciso caracterizar os estrangeiros e os bárbaros e não apenas os que se situavam fora dos limites da cidade e do Império, mas os que estavam em seu interior.

Parece-me que, em meados do XIX, a recuperação dos feitos de Enéias e sua postura diante de "submissos e soberbos" pode ser considerada suporte metafórico tanto de propositura, aparentemente irrecusável, para que os contendores da luta política se desarmassem, quanto de violenta definição de identidades e alteridades, engendradas no processo de configuração do Império e da nação. Estavam em jogo as fronteiras entre ser reconhecido como "cidadão" e "não cidadão", bem como entre ser brasileiro e ser estrangeiro, incluindo-se ,nesse campo, o português. Em termos da "conciliação" proposta na década de 1850, encontrava-se em pauta, sobretudo, a reafirmação de instrumentos de soberania do Estado imperial, inscritos na Carta de 1824, postos em operação naquele momento pelo grupo dirigente que os manejava para vencer múltiplas resistências. Assim, havia diferentes categorias de "soberbos" a debelar, entre os quais se situavam as facções conservadoras dissidentes da política econômica e partidária encaminhada pelo gabinete Paraná, e que foram atingidas por autoridades pertencentes ao próprio partido 9 .

Nesse sentido, construtores e herdeiros não estariam apenas encarnados nos políticos e empreendedores envolvidos na Independência. Também assim se apresentaram à esfera pública os que atuaram nas Regências e posteriormente na reorganização política e partidária das décadas de 1840 e 1850. Além de não representarem etapas na trajetória deste ou daquele protagonista, essas noções poderiam ser interpretadas como manifestação simultânea de movimentos de luta política e de elaboração da memória dessas mesmas lutas, exteriorizações concretas e imaginárias da formação do Império do Brasil.

Atenta-se, desse modo, para a outra dimensão que julgo pertinente destacar e que foi amplamente discutida por Claude Lefort. Analisando o 18 Brumário, o autor procurou mostrar que Marx registrou a multiplicidade de antagonismos sociais na França em meados do século XIX, sublinhando a articulação entre inúmeras histórias, ancoradas em diferenciados protagonistas 10 . Mais ainda: ao apontar a impossibilidade de distinguir nas lutas do periodo "a ordem da realidade da ordem da fantasmagoria", Marx interrogava os fundamentos da ação dos atores e dos acontecimentos que provocavam, ora cogitando não passarem de "sombras que perderam os corpos", ora buscando reconstituir, no encadeamento dos episódios, os interesses em confronto e o não reconhecimento imediato deles por parte de indivíduos e facções de classes. Frente à "vertigem" que seus projetos, decisões, palavras e intrigas ensejavam, os protagonistas da história procuraram se defender das rupturas na continuidade do tempo, evocando os mortos, disfarçando o presente em passado, inventando um passado.

Esse referencial possibilita pensar a construção do Império do Brasil como algo inédito, que rompia irremediavelmente com a situação política e as tradições anteriores. As linhas de continuidade entre a monarquia portuguesa e o Império do Brasil seriam engendradas pelo modo peculiar através do qual, em meio a suas lutas e seus interesses, os protagonistas recriaram o passado como representação, como escudo e guia, para enfrentar as "experiências emocionantes" da "revolução" que envolviam a brava gente brasileira, flagrada por IImar Mattos no hino escrito por Evaristo da Veiga, em $1822^{11 .}$

Se insisto nesse ponto, nesses liames difíceis de precisar entre presente e passado, entre história e memória, entre atores, acontecimentos e repre- 
12

Ver, especialmente, Sérgio B. de Holanda. "A herança colonial - sua desagregação", In: História Geral da Civilização Brasileira. Tomo II, $1^{\circ}$ vol. $3^{a}$ ed. São Paulo: Difel, 1970, pp. 9-40.

\section{3}

Maria Odila da Silva Dias. "A interiorização da metrópole, 1808-1852". In: Carlos Guilherme Mota (org). 1822: Dimensões. São Paulo: Perspectiva, 1972, pp.160-184.

14

Refiro-me, aqui, à periodização "desenhada" por Caio Prado Jr em Evolução Política do Brasil e outros estudos. $5^{\text {a }}$ ed. São Paulo: Brasiliense, 1966.

15

IImar R. de Mattos. Tempo saquarema. São Paulo: Hucitec/ INL, 1987.

\section{6}

Cabe ressaltar que algumas das implicações de se considerar a data de 7 de setembro de 1822 como marco divisório da história do Brasil foram tratadas por Maria de Lourdes Viana Lyra em obra já citada e também em artigo publicado na Revista Brasileira de História, n² 29, 1995. Sobre o processo de conformação da memória de 7 de setembro e sobre a impossibilidade de se interpretar Independência e separação de Portugal como sinônimos, consultar: Cecilia Helena de Salles Oliveira. A Astúcia Liberal. São Paulo: Ícone/ USF, 1999; e da mesma autora 0 Espetáculo do Ypiranga: mediações entre história e memória. Tese de livre-docência. São Paulo, Museu Paulista da USP, 2000.

17

IImar R. de Mattos. Tempo Saquarema, Introdução e pp. 129-ss.

18

Sérgio Buarque de Holanda.0p. cit., pp. 13-15.

19

Maria Odila da Silva Dias. Op.cit., pp. 161-162 e 175-ss. sentações, é porque o artigo de Ilmar Mattos trata do peso das heranças na configuração do Império - o nome, o território, a concepção dinástica, a cidade do Rio de Janeiro associada à "cabeça" do corpo político - não para abordá-las como fardo, como geralmente ocorre, mas para propor a enorme capacidade inventiva e criadora dos políticos que vivenciaram a separação de Portugal, bem como a organização do Estado e da nação. Seus olhos estão concentrados no movimento de construção, mas para descrevê-lo desdobra o processo no qual as heranças foram reinventadas, quer na dimensão da prática política, quer na do discurso e da memória. Por esse caminho, convida o leitor a reconsiderar as vertentes interpretativas mais conhecidas sobre o tema e o período, distanciando-se delas.

\section{Império do Brasil: a construção da nação e a "teia de Penélope"}

Ao tecer seus argumentos, IImar Mattos, à primeira vista, estaria se colocando em campo historiográfico próximo ao de Sérgio Buarque de Holanda ${ }^{12}$ e Maria Odila da Silva Dias ${ }^{13}$. Mas, se compartilha com esses autores, bem como com Caio Prado Júnior ${ }^{14}$, o questionamento da associação imediata entre a separação de Portugal e o delineamento do Império, isso não significa concordar com outros pressupostos defendidos por esses historiadores.

Na obra Tempo Saquarema15, editada pela primeira vez em 1987, o autor já havia indicado a impossibilidade de confundir a formação da nacionalidade com eventos circunscritos, a exemplo da proclamação de 1822 e da abdicação, em 183116. Na ocasião, evidenciou de que modo, entre 1838 e 1860, desdobrou-se o movimento simultâneo de construção do Estado imperial, da classe senhorial, e dos dirigentes saquaremas - denominação que abrangia tanto a alta burocracia radicada na Corte, quanto as demais personagens da rede politica e de interesses, que articulava segmentos proprietários e autoridades provinciais à cidade "cabeça do Império" 17.

Entretanto, isso não significa desqualificar o marco 1822. Particularmente no artigo em foco, Mattos contraria Buarque de Holanda, para quem a proclamação da Independência não teria passado de episódio de uma "guerra civil entre portugueses", e a opção pela monarquia e pela dinastia de Bragança seriam sinônimos de "despotismo" ou "retrocesso"18. Realça a pertinência de se compreender a dimensão "revolucionária" e apaixonada que os protagonistas atribuíram às experiências políticas em curso nas décadas de 1820 e 1830, diferenciando-as igualmente da forma pela qual, muito tempo depois, Machado de Assis formularia a fria atitude de Brás Cubas frente às circunstâncias da emergência da nação, quando a personagem, depois de longa estadia na Europa, retornou ao Rio de Janeiro.

Por outro lado, a proposta apresentada no artigo, segundo a qual a construção do Império implicou um processo de "expansão para dentro", não se coaduna com a concepção de "interiorização da metrópole". Maria Odila, que cunhou a expressão, procurou por meio dela destacar o fortalecimento da presença portuguesa e a implementação de "movimento interno de colonização", promovidos com a chegada da Corte ao Rio de Janeiro, em 1808, aspectos relevantes e que, desde então, vêm compondo o elenco de problemas sobre o qual se debruça a historiografia referente à época.

Contudo, seguindo a trajetória de Buarque de Holanda, a historiadora atribuiu "caráter reacionário, contra-revolucionário e absolutista" aos episódios da Independência, considerando que, frente às repercussões da Revolução de 1820 e à visibilidade das contradições sociais e raciais provocadas por ela no Brasil, ocorreu uma "reação conservadora das elites" 19. Desvencilhando os confrontos entre "portugueses do Reino e portugueses da América", em 1822, dos condicionamentos que transformaram a Corte do Rio de Janeiro no eixo de formação do Estado e da nação, Dias atrelou a gênese do Império do Brasil a projetos forjados, nos fins do século XVIII, por ilustrados portugueses e "luso-brasileiros". Foram estes que compuseram, juntamente com os setores 
A tese da "interiorização da metrópole" e a interpretação de que o processo de separação de Portugal e de Independência teve perfil conservador, representando uma continuação de projeto de organização de Império português concebido no século XVIII, foram amplamente desenvolvidas por Paula Porta Fernandes. Elites dirigentes e projeto nacional. Tese de doutorado. São Paulo, Universidade de São Paulo, Faculdade de Filosofia, Letras e Ciências Humanas., 2000. Cabe lembrar que as relações entre projeto de Império português e Império "brasílico" foram discutidas em profundidade por Maria de Lourdes Viana Lyra. A Utopia do poderoso Império. Rio de Janeiro: Sette Letras, 1994. Entretanto, a historiadora, mesmo reconhecendo imbricações entre essas propostas, abre espaço para se pensar que, simultaneamente, a elas foram se constituindo outros projetos de cunho reformista e revolucionário tanto em Portugal quanto na América portuguesa, particularmente no início do século XIX. Assim, ao invés de lidar com a inexorabilidade da feição conservadora do Império do Brasil, optou por investigar algumas das razões pelas quais esse perfil preponderou.

\section{1}

Balanços e análises sobre a historiografia que trata da Independência e da fundação do Império podem ser encontrados no livro A Astúcia Liberal, já mencionado, bem como no artigo de István Jancsó e João Paulo Garrido Pimenta, "Peças de um mosaico". In: Carlos Guilherme Mota (org.), Viagem Incompleta. A experiência brasileira (15002000).Formação: histórias, vol. 1, São Paulo: SENAC, 2000. Mais recentemente, Wilma Peres Costa realizou estudo circunstanciado a respeito das principais linhas de interpretação construída em torno da Independência, estudo que foi apresentado no Seminário Internacional "Independência do Brasil: história e historiografia", realizado na USP, em 2003. 0 artigo, intitulado "A Independência do brasil na historiografia brasileira" encontra-se disponivel no site www.ieb.usp.br.

\section{2}

Ver: "Império" em Ronaldo Vainfas (dir). Dicionário do Brasil Imperial. Rio de Janeiro: Objetiva, 2002, pp. 356-358.

\section{3}

Luiz Felipe Alencastro. "L'Empire du Brésil". In: Maurice Duverger (dir). Le concept d'empire. Paris: Presses Universitaire de France, 1980, pp. 301-309.

\section{4}

José Honório Rodrigues. Independência: revolução e contra-revolução. 5 vols. São Paulo: Francisco Alves, 1975. mercantis mais ricos da sociedade colonial, as elites que, de forma unânime e "coesa", teriam gerenciado não só o movimento separatista como a definição das bases da monarquia no século XIX20.

É esta vertente interpretativa que ainda prepondera na literatura especializada e em obras de divulgação, apesar do considerável alargamento das pesquisas sobre a temática e o periodo, especialmente nos últimos vinte anos ${ }^{21}$. 0 verbete "Império" no Dicionário do Brasil Imperial, por exemplo, reproduz e reforça a tese da "interiorização da metrópole" e do extremo conservadorismo que a sustentou, o que contribui, a meu ver, para obscurecer as feições matizadas e complexas dos confrontos sociais e dos debates politicos naquele período. Não apenas foi sublinhada uma relação de imediata continuidade entre o "Império luso-brasileiro" e o Império do Brasil, como se cogitou a idéia de que a separação de Portugal representou a "preservação" literal de instituições e práticas consolidadas com a reorganização da Corte no Rio de Janeiro. Segundo o texto, se Pedro I "encarnava" o projeto de um império com primazia portuguesa, os regentes e a elite política do centro-sul teriam progressivamente conseguido das demais elites regionais a aquiescência em torno da Constituição de 1824, dado o temor de todos frente "à desordem e ao caos" ensejados pela presença de oprimidos, libertos e escravos ${ }^{22}$.

Mesmo a interpretação de Luiz Felipe de Alencastro não se afastou de algumas dessas premissas ${ }^{23}$. A seu ver, D.Pedro e os "funcionários reais" que permaneceram no Rio de Janeiro depois do retorno da Corte a Lisboa, em 1821, teriam agido "em simetria" à atuação das Cortes em Lisboa, unindo "numa mesma plataforma a afirmação do poder monárquico e os desejos de liberação nacional expressos pelas classes dominantes brasileiras". Para o autor, foi nessa atmosfera de "absolutismo revolucionário" que se decidiu a proclamação da Independência do Brasil e a fundação do Império, por intermédio de uma justaposição entre elementos novos e antigos. Mas o processo político seria sobretudo o desdobramento "de toda uma corrente ideológica portuguesa que prolongou os desejos milenaristas da Reconquista e do movimento de expansão marítima lusitana". Este aspecto, aliado à longevidade e ao fato da unidade política fundamentar-se em torno de um Estado centralizador, capaz de garantir acordos comerciais internacionais e a manutenção do tráfico atlântico de escravos, marcariam a singularidade da formação política adotada no Brasil no século XIX.

Ao reconstituir o periodo, IImar Mattos propõe reflexões que problematizam esses modos de compreensão, mas igualmente se distanciam de versões que aliam Independência e revolução "nacionalista", a exemplo daquilo que defendeu José Honório Rodrigues ${ }^{24}$. Suas considerações, sem diminuir o peso das heranças políticas da monarquia portuguesa e, portanto, as implicações do chamado reformismo ilustrado e da reorganização da Corte bragantina em terras cariocas a partir de 1808, abrem a possibilidade de investigar historicamente as re-significações que elas adquiriram, uma vez que interroga, ao mesmo tempo, o processo histórico e o registro desse processo, o que está exemplarmente expresso na análise do Hino Constitucional Brasiliense com o qual inicia o artigo.

É a emergência de projetos incongruentes acerca do caráter e das dimensões da "nação" que adquire importância quando o autor indaga sobre a transformação histórica do nome "Império do Brasil", do território e sua configuração e do papel assumido pela cidade do Rio de Janeiro. Mas, obra politica, bases materiais, assim como a associação entre a urbe carioca e um centro soberano de decisões, não são vistos na condição de dados brutos que caberia ao historiador explicar. 0 que está em causa é, por um lado, a "trama de interesses", de circunstâncias e de protagonistas, sempre fluida e cheia de alternativas, na qual Império, território, Corte e nação se configuraram historicamente. $E_{1}$ por outro, as interpretações que os atores deixaram do tempo que viviam e construiam. 
IImar R. de Mattos, Tempo Saquarema, pp. 286-287.

\section{6}

Quando me refiro às contradições internas à sociedade colonial e, a partir delas, à impossibilidade de compreender a nação e o Império como entidades acabadas, seja do ponto de vista histórico, seja do ponto de vista político, referencio-me em observações de Claude Lefort sobre as chamadas sociedades "históricas". Na interpretação do filósofo "o próprio de uma sociedade histórica é que ela contém o princípio do acontecimento e tem o poder de convertê-lo em momento de uma experiência, de modo que ele figura um elemento do debate que se processa entre os homens. Nela a transformação não é essencialmente a passagem de um estado para outro, mas o encadeamento desse debate que antecipa sobre o futuro referindo-o ao passado..." Para Lefort, o movimento de apropriação e tematização do passado é simultâneo à produção de sentido, à abertura ao novo e à antecipação do futuro. Ver Claude Lefort. As formas da história. São Paulo: Brasiliense, 1979, pp.47-48. Na obra Tempo Saquarema, Ilmar Mattos também fez referência a essas questões, articulando o "tempo saquarema" às maneiras especificas de pensar a origem da nação brasileira, a própria instituição da sociedade e suas possibilidades de transformação. Esse modo de pensar, produzido histórica e politicamente seria, ainda, a matriz de muitas interpretações historiográficas sobre 0 Império. Op. cit., pp. 284-285.

\section{7}

Ver a esse respeito, entre outros, a obra já citada de Maria de Lourdes Viana Lyra, bem como os livros de Márcia Berbel. A nação como artefato. São Paulo: Hucitec/FAPESP, 1999; Valentim Alexandre. Os sentidos do Império. Porto: Afrontamento, 1993; e de João Paulo Garrido Pimenta. Estado e nação no fim dos Impérios ibéricos no Prata, 1808-1828. São Paulo: Hucitec, 2002.

\section{8}

Conferir, entre outros: Paula Beiguelman. Formação política do Brasil. 2 vols. São Paulo: Pioneira, 1967; Alan Manchester. Preeminência inglesa no Brasil. São Paulo: Brasiliense, 1973; Luiz Felipe Alencastro. $O$ trato dos viventes. São Paulo, Companhia das Letras, 2000; João Fragoso. Homens de grossa aventura. Rio de Janeiro: Arquivo Nacional, 1992; Manolo Florentino Em costas negras. São Paulo: Companhia das Letras, 1997; João Fragoso, Maria de Fátima Gouvêa e Maria Fernanda Bicalho (orgs). 0 Antigo regime nos trópicos. Rio de Janeiro: Civilização Brasileira, 2001.

\section{9}

Ver, entre outros, os ensaios de Alberto da Costa e Silva reunidos no livro Um rio chamado Atlântico. Rio de Janeiro: Nova Fronteira/ UFRJ, 2003.
IImar Mattos, no livro já citado, chamou a atenção para o comprometimento de parcela significativa da historiografia do Império com a dominação exercida pelo "tempo saquarema" sobre a memória e o entendimento do passado 25 . Seguindo-se o argumento, é possivel então ampliar as significações da expressão "poupar submissos debelar soberbos", usada como palavra de ordem em diferentes ocasiões da política imperial, especialmente nos anos de 1840 e 1850 . Submissos e soberbos não adjetivavam apenas, e de modo propositadamente simplificado nos discursos dos protagonistas, partidários e adversários de proposições praticadas pelos grupos que ocuparam os espaços de poder em momentos históricos específicos. Subordinava-se o passado a essas designações e, em nome do "progresso" material e moral, desqualificavam-se heranças, protagonistas, eventos, projetos e conflitos anteriores, toldando-se o campo de forças sociais em que se definiu historicamente 0 Império e sua direção.

Quando Ilmar Mattos sugere a dificuldade de tomar-se o Império como resultado direto e linear de um projeto gerado, nos finais do século XVIII, no interior da monarquia portuguesa, o que procura é discutir, no âmbito da dinâmica social e da memória, como as heranças foram recriadas sob condições inéditas, recuperando as divergências entre "portugueses da América e portugueses da Europa", e reconstituindo o contexto mais amplo no qual se inscreviam os impasses experimentados por diferenciados setores sociais radicados em Portugal, no Reino do Brasil e na África, todos eles entrelaçados por interesses imediatos e perspectivas futuras. As linhas de continuidade aparecem, assim, mediatizadas pelo passado, que se reveste de sentidos múltiplos dependendo dos interlocutores e dos lugares sociais que ocupam, e pelo futuro no qual se projeta um Império que, apesar da tangibilidade e das feições que adquiriu ao longo do século XIX, parece existir como possibilidade histórica sempre reposta e nunca finalizada, dadas as contradições internas à sociedade 26 .

Como lembrou o autor, no complexo movimento de definição do Império essas contradições estiveram imbricadas a acontecimentos e decisões que superaram o campo de ação de políticos e empreendedores no Brasil, em razão da simultaneidade na qual também na Europa e no restante da América, guardadas as especificidades históricas, estavam em curso processos de configuração de nações e Estados nacionais. Assim, no início do século XIX foram enfrentamentos em relação às Cortes em Lisboa e conflitos no Rio de Prata que monopolizaram debates e encaminharam alguns dos limites diante dos quais se deteve aquela definição27.

Mas, além disso, o Império do Brasil enfrentou outro império em formação - o britânico. Há inúmeros estudos a respeito desses confrontos, bem como sobre a rede de negócios que articulava interesses radicados no Brasil e na África desde o periodo colonia|28. Essas análises vêm modificando o entendimento tanto das relações dos domínios portugueses entre si, quanto dos nexos entre interesses portugueses (da América e do Reino), africanos, britânicos e norte-americanos em torno do tráfico de escravos. Ademais, vêm sendo discutidos os procedimentos britânicos para reduzir e abafar, na primeira metade do século XIX, a presença mercantil de portugueses americanos, num primeiro momento, e depois, de brasileiros, no continente africano 29.

Para Ilmar Mattos não é casual a coincidência entre o arrefecimento da atuação de negociantes e traficantes brasileiros na África e a associação entre Império do Brasil e nação brasileira nos discursos de dirigentes na Corte do Rio de Janeiro, particularmente nas décadas de 1840 e 1850. A associação entre Império e nação significou não só uma alternância de sentido - a mudança da concepção dinástica de Império para a concepção nacional - como o fortalecimento de uma direção política: frente à impossibilidade de um domínio ilimitado em termos espaciais, o Estado empreendeu uma 
30

Sobre a noção de império e as diferentes tentativas de conceituação em termos da teoria política, consultar: Michel Chartier. "Impérios". In: Enciclopédia Einaudi. Vol 14. Lisboa: Casa da Moeda/ Imprensa Nacional, 1989, pp. 318329; Maurice Duverger. "Le concept d'empire". In:__ (org). Le concept d'empire. Paris: Presses Universitaire de France, 1980, pp. 5-23; Paolo Colliva. "Imperio". In: N. Bobbio, N. Matteucci. e G. Pasquino (dir). Dicionário de Politica. Vol 1.Trad. Varriale et alli. 12a ed. Brasilia: UnB, 1999, pp. 621-626. "expansão para dentro", voltada para a configuração da nação e da cidadania, bem como para a definição das diferenciações e hierarquizações que sublinharam a existência de outras "nações" no interior da nação brasileira.

Em que medida, porém, a interpretação centrada na "expansão para dentro" se diferencia da noção de "interiorização da metrópole"? Ambas não teriam como pressuposto o predomínio quase hegemônico de projeto político conservador desde o movimento de Independência? Acredito que a argumentação exposta por Mattos desmente uma provável sinonímia entre essas expressões. Penso, também, que, entre outros aspectos e questões, a originalidade da contribuição de Mattos reside em buscar referências mais amplas para compreender o Império do Brasil, do ponto de vista da teoria política e da especificidade histórica do processo então em curso. São precisamente esses referenciais que demarcam a distância entre uma interpretação e outra.

Em termos da teoria política, de forma geral, a expressão império aparece vinculada a algumas condições singulares que, supostamente, poderiam servir de parâmetro para a compreensão de episódios históricos diversos em termos temporais e espaciais, como observou Maurice Duverger. Assim, um Império seria um sistema político criado sobre vasta extensão territorial, reunindo um conjunto heterogêneo de etnias e culturas, constituído por meio de conquista militar, a qual se aliam outras formas menos perceptiveis de mando e imposição. Suas bases de sustentação estariam em uma estrutura centralizadora de poder, suficientemente extensa e eficaz para controlar os fluxos econômicos, transferir as riquezas geradas das diferentes localidades para um centro político que emblematicamente representasse o todo, e impor princípios políticos e culturais sem desfazer, entretanto, o "mosaico" de povos e situações diversificadas que agrega ${ }^{30}$. Inspirado em grande medida na experiência romana e nas formas pelas quais foi interpretada e divulgada, particularmente no século XIX, esse conjunto de características, quase um modelo, dificilmente poderia ter aplicação, a não ser sob o risco de anacronismo. Mas, nele há um elemento-chave que foi recuperado por IImar Mattos: a relação entre Império e conquista.

Considero ser esta relação um ponto de clivagem entre a interpretação formulada pelo autor e as demais análises citadas. No caso em questão, a conquista implica reconhecer que o processo de configuração do Império do Brasil foi engendrado no interior de uma sociedade matizada que abrigava, em função disso, diferentes projetos políticos. A hegemonia alcançada pelo projeto conservador de Estado, em meados do século XIX, foi construída por meio de guerras e conflitos de diferentes naturezas, que envolveram desde a luta armada e manifestações de rebeldia de escravos, libertos e homens livres pobres, até a luta por espaços de representação parlamentar e diretiva. Entretanto, essa hegemonia não significou o desaparecimento de outros projetos políticos, nem nas décadas de 1840 e 1850, tampouco posteriormente. Por outro lado, seria muito simplificado imaginar que a imposição das propostas conservadoras coincidiu com ocupação e colonização no território até porque os confrontos que marcaram a construção da nação e do Estado nacional - o Império como refere Mattos - não se limitaram aos segmentos proprietários e aos setores mais ricos da sociedade. Submeter soberbos, para retomar as metáforas de Virgílio recriadas pelos políticos brasileiros que articularam a "conciliação", não diz respeito apenas ao processo civilizatório, em seu significado cultural mais amplo. Pois, o que estava em jogo no Brasil, na primeira metade do século XIX, e de maneira semelhante ao que acontecia em outros lugares, eram a supressão da legislação colonial e a substituição das regulamentações do chamado Antigo Regime por outros instrumentos que vieram a consolidar o "laissez faire" bem como liberar o mercado e os processos de acumulação de procedimentos considerados tradicionais. Ou seja, quando se fala em interiorizar a metrópole sugere-se a expansão de princípios e práticas herdados e já acabados, obliterando-se o movimento histórico de transfor- 
31

Isabel Marson. Op.cit., cap. 4.

32

Cecília Helena de Salles Oliveira. "Tramas políticas, redes de negócio". In: István Jancsó (org). Brasil: formação do Estado e da nação. São Paulo: FAPESP/Hucitec/ UNIJUi, 2003, p. 400.

33

IImar R. Mattos. Tempo Saquarema., p. 284. mação desses princípios, as rupturas, as descontinuidades e os desvios dessa expansão, e, especialmente, esquecendo-se que ao longo do percurso os atores também se alteraram e modificaram, em razão das próprias experiências, de suas lutas, reivindicações, procedimentos e idéias.

0 Império que José Bonifácio havia imaginado era muito diferente daquele pelo qual Evaristo da Veiga lutou. E a obra política que a "conciliação" procurava reafirmar, ainda que fincada na Constituição de 1824, estava muito distante do debate no qual o documento foi produzido. Mesmo em termos dos espaços para o exercício da cidadania, é forçoso reconhecer, como observou Izabel Marson em obra citada31, como a concepção de "cidadão" se modificou em meados do século XIX, seja em razão do debate em torno das formas de acumulação e investimentos de capitais, seja em função do fato de que as propostas de modernização das atividades econômicas estavam imbricadas à transformações nas relações de trabalho escravistas e aos modos de apropriação da mão-de-obra dos contingentes de lavradores, posseiros, índios e, depois, setores de homens livres e libertos.

Nesse sentido, a relação Império/conquista pode abrigar os conflitos políticos e econômicos que opuseram e/ou aproximaram diferenciados segmentos sociais proprietários, em momentos históricos particulares, na primeira metade do século XIX. Ao mesmo tempo, incorpora o denso e matizado elenco de confrontos protagonizados pelos múltiplos setores da sociedade que haviam se constituido no Brasil e reivindicavam não só liberdade de atuação como a possibilidade da cidadania. Agasalha, ainda, a percepção central, a meu ver, de inacabamento. Não na direção de que o nexo entre Império e nação tenha se constituído pela metade ou que, em função da escravidão, a nação não teria se configurado. Em outra ocasião, já tive a oportunidade de observar que, do ponto de vista da prática e do pensamento liberais, a figura do escravo desdobra, até as últimas conseqüências, as concepções de propriedade individual e de mercado soberano, bem como as relações de dominação e desigualdade entre cidadãos e excluídos da sociedade. 0 que conduz à compreensão de que os fundamentos da cidadania e a tangibilidade da nação brasileira estavam indissoluvelmente articulados à escravidão32.

0 inacabamento refere-se ao que IImar Mattos denominou "permanente recomeçar e eterno desfazer", simbolicamente expresso pela "teia de Penélope"33. Trata-se da teia de relações que conservava e dava concretude à obra do Império, mas que se encontrava, ao mesmo tempo, permeada pelas contradições, pelos confrontos entre grupos e projetos, e pelas múltiplas possibilidades históricas de transformação. 